\title{
Observations of Low Charge State Impurities in EBT
}

\author{
E. S. Warden \\ H. W. Moos \\ N. H. Lazar
}




\section{DISCLAIMER}

This report was prepared as an account of work sponsored by an agency of the United States Government. Neither the United States Government nor any agency Thereof, nor any of their employees, makes any warranty, express or implied, or assumes any legal liability or responsibility for the accuracy, completeness, or usefulness of any information, apparatus, product, or process disclosed, or represents that its use would not infringe privately owned rights. Reference herein to any specific commercial product, process, or service by trade name, trademark, manufacturer, or otherwise does not necessarily constitute or imply its endorsement, recommendation, or favoring by the United States Government or any agency thereof. The views and opinions of authors expressed herein do not necessarily state or reflect those of the United States Government or any agency thereof. 


\section{DISCLAIMER}

Portions of this document may be illegible in electronic image products. Images are produced from the best available original document. 


\section{Printed in the United States of America. Available from National Technical Information Service \\ IIS Mepartment of Commorcc \\ 5285 Port Royal Road, Springfield, Virginia 22161 \\ Price: Printed Copy $\$ 4.00$; Microfiche $\$ 3.00$}

This report was prepared as an account of work sponsored by the United States Government. Neither the United States nor the Energy Research and Development Administration/United States Nuclear Regulatory Commission, nor any of their employees, nor any of their contractors, subcontractors, or their employees, makes any warranty, express or implied, or assumes any legal liability or responsibility for the accuracy, completeness or usefulness of any information, apparatus, product or process disclosed, or represents that its use would not infringe privately owned rights. 
Contract No. W-7405-eng-26

FUSION ENERGY DIVISION

\title{
OBSERVATIONS OF LOW CHARGE STATE IMPURITIES IN EBT
}

E. S. Warden and H. W. Moos

Johns Hopkins University

Baltimore, Maryland 21218

United States of America

and

N. H. Lazar

Oak Ridge National Laboratory

This teport was prepared as an account of work sponwored by the United States Government. Neither the United States nor the United States Energy Reearsh and Revelopment Administrotion, nos any of subcontractors, nor any of their contractors, warmanty, express or implied, or asummes any lagel tiability of responsibility for the accuracy, completenes or usefulness of any information, apparatus, product or process disclosed, or represents that its use would not Oak Ridge, Tennessee 37830 infringe privately owned rights.

[To be submitted to Nuclear Fusion (Letters) for publication.]

\author{
Manuscript Completed - April 1977 \\ Date Published - May 1977
}

NOTICE This document contains information of a preliminary nature. It is subject to revision or correction and therefore does not represent a final report.

Prepared by the

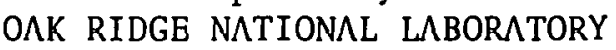

Oak Ridge, Tennessee 37830

operated by

UNION CARBIDE CORPORATION

for the

ENERGY RESEARCH AND DEVELOPMENT ADMINISTRATION

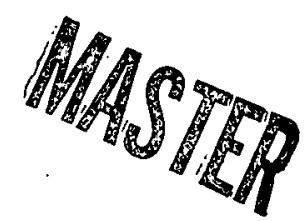




\begin{abstract}
Spatially resolved profiles of low charge state carbon and aluminum ion impurity radiation from EBT were obtained in the vacuum ultraviolet. The data shows EBT to be remarkably free from impurities. Loss times in the surface plasma are found to be approximately $300 \mu \mathrm{sec}$. Thus about one fourth of the input power supports the surface plasma. The measurement places an upper limit on the $\mathrm{C} \mathrm{V}$ density in the core plasma which indicates that the core plasma is shielded from the impurities in the surface plasma.
\end{abstract}


This letter reports an initial study of impurity ions in EBT. Impurities are of central concern in toroidal fusion devices, because their presence in the hot plasma regions would influence both particle confinement and energy 10ss. Further, the interface betwecn the energetic plasma and the vacuum wall is filled with a cooler surface plasma whose sustenance is a power drain which must ultimately be considered in power balance considerations. In the steady-state ELMO Bumpy Torus (EBT) [1] concept, particular care must be taken that this surface plasma both acts as an effective ionization shield for incoming impurities and consumes minimum power in reactor configurations.

We have obtained quantitative, spatially resolved density measurements for the various carbon and aluminum charge states in order to establish the ion lifetimes. These measurements, based primarily on the vacuum ultraviolet resonant line intensities, were made using a miniature Ebert ultraviolet spectrometer calibrated at Johns Hopkins University against NBS standards [2].

The experimental geometry is shown in Fig. 1. Light from the plasma passes through a slot in the midplane of one of the 24 microwave cavities of EBT. To prevent the escape of microwave radiation, the slot is covered with a $30 \%$ average transmission microwave cutoff screen. The light st.rikes a rotatable scanning mirror and is deflected. One particular set of rays defining a chord across the plasma is selected by a mask. These rays pass $2.5 \mathrm{~m}$ down an evacuated tube through the $\mathrm{x}$-ray wall surrounding EBT and strike a focusing mirror which focuses the selected set of rays onto the entrance slit of the 1/8-m Ebert spectrometer. 
The reflection of plasma light from the cavity walls is a possible source of error in the measurement. This light has been greatly reduced by an optical trap in the midplane opposite the scanning mirror. This trap consists of recessed wells in the cavity walls viewed by the scanning mirror with cover plates which are drilled with a hexagonal, close-packed array of small holes. The scattered light is reduced by more than an order of magnitude.

The spectral range covered during the course of the measurements was 1150-2400 ̊. The detection electronics are operated in a pulse counting mode, and a baffle acting as a mirror stop is adjusted so that dead time corrections are negligible.

Originally designed as a rocket instrument, the spectrometer has a theoretical resolving power of 90,000 . It was operated here with a resolution of one angstrom, which was sufficient to resolve or partially resolve most of the identified carbon and aluminum multiplets. Impurity lines of C II, C III, C IV, A1 II, and A1 III were identified. These lines were rather simply connected to the ground state or the metastable state.

Al1 uptical components were absolutely calibrated at Johns Hopkins University both before and after data runs. The degradation in quantum transmission between calibrations was typically $10 \%$. Thus, changes in calibration should not affect the quality of the data.

Because of the lack of symmetry of the drift surfaces in EBT, it is not simple to extract density distributions with high precision from this single view of the plasma but simple models of particular plasma 
regions do, in fact, yield approximate results. Shown in Fig. 2 are spatial scans of some of the emission line intensities which have been partially analyzed.

The EBT plasma [1] is composed of two components: a hot, toroidal, core plasma and a colder surface plasma. Due to a combination of geometric effects and single particle drifts, the loss rates in the surface plasma are much greater than in the toroidal plasma, leading to highcr electron temperature and densities in the toroidal core $(\sim 300 \mathrm{eV}$; $\left.2 \times 10^{12} \mathrm{~cm}^{-3}\right)$ than in the surface plasma $\left(\sim 50 \mathrm{eV} ; 3 \times 10^{11} \mathrm{~cm}^{-3}\right)$. Analysis of the loss rates in the surface plasma can be made by restricting data analysis to those chords which do not pass through the toroidal region.

The excitation rate for all observed species is a rather insensitive function of electron temperature as the excitation energies are about 10 eV. An electron temperature of $50 \mathrm{eV}$ was assumed in calculating excitation rates from the formula [3]

$\langle o v\rangle=3.2 \times 10^{-7} \frac{\mathrm{f}_{\mathrm{ik}}<\dot{\mathrm{g}}>\sqrt{\mathrm{x}} \mathrm{e}^{-\mathrm{x}}}{\left(\frac{\Delta \mathrm{E}_{\lambda}}{13 . \sigma}\right)^{3 / 2}} \mathrm{~cm}^{3} / \mathrm{sec}$

where $f_{i k}$ is the oscillator strength of the Lransition taken from Wiese; Smith, and Glennon [4] or from Hummer and Norcross [5]; $\Delta E_{\lambda}$ is the energy of the transition in electron volts; $x=\Delta \mathrm{E} / \mathrm{T}_{\theta} ;$ and $\langle\mathrm{g}\rangle$ is a semi-empirical term given by Van Regemorter [6]. For $\mathrm{T}_{\mathrm{e}} \gg \Delta \mathrm{E}_{\lambda}$, the term $\langle\overline{\mathrm{g}}\rangle \sqrt{\mathrm{x}} \mathrm{e}^{-\mathrm{x}}$ is $\sim 0.1-0.15$ over a very large range of energy.

For C II, C III, and Al II a considerable number of ions are in metastable levels. Direct measurements of the ground state and 
metastable population were made for C III and AI II. The C II and C III metastable populations were assumed to be the same as those obtained from previous measurements through the center of the midplane. Table I gives values of the product $\mathrm{n}_{e} \mathrm{n}_{i}$ integrated along the line of sight for several scan angles. Except for the scan angle of $0^{\circ}$, the line of sight for these scan angles passes only through the surface plasma and does not intersect the toroidal plasma. The ion charge states for ions of a given atomic number are connected through the rate equations

$\frac{d n_{j}}{d t}=n_{e} n_{j-1} S_{j-1}-n_{e} n_{j} S_{j}-\frac{n_{j}}{T_{j}}+n_{e}{ }^{n_{j+l} R_{j+l}}-n^{n_{j} R_{j}}$

where $n_{e}$ is the electron density, $n_{j}$ is the ion density of the $j$ th charge state, $s_{j}$ is the rate coefficient for ionization of species $j$, $R_{j}$ is the rate coefficient for recombination of species $j$, and $\tau_{j}$ is the loss time.

In a steady-state machine such as EBT, all quantities are independent of time. The recombination rate coefficients for low charge states in the density and temperature range of EBT are also sufficiently small that these processes may be neglected. With these simplifications, a solution for $\mathrm{n}_{\mathrm{e}^{\top} \mathrm{j}}$ may be written as $\left(n_{e}{ }^{\top}\right)^{-1}=S_{j-1}\left\{\frac{n_{j-1}}{\tilde{n}_{j}}-\frac{s_{j}}{S_{j-1}}\right\}$

A Ineasurement of the ratio of the ion densities thus forms the basis of a good measurement of the ion loss times for $n_{e}{ }^{T} j$ not much greater than the inverse of $s_{j-i}$. Alternately, a knowledge of $n_{e}{ }^{\tau}$ permits a prediction of the ratio of the densities of two adjacent charge states: 
$\frac{n_{j}}{n_{j-1}}=\frac{n_{e}{ }^{\tau}{ }_{j} S_{j-1}}{1+n_{e}{ }^{\top} S_{j}}$

Provided the inverse of $\mathrm{n}_{\mathrm{e}^{\top} \mathrm{j}}$ is much larger than the recombination rates, the above formula is valid even in the case where ionization and recombination rates in Eq. (2) are comparable.

Table II lists the values of $n_{e^{\tau}}$ calculated from the values of $\mathrm{n}_{\mathrm{e}^{\mathrm{n}} \mathrm{j}}$ given in Table $\mathrm{I}$. The ionization rate coefficients used in the 'calculation were those given by Lotz [7-8]. (Kunze [9] reports on the basis of experimental results that the ionization rate coefficients given by Lotz appear to be too high by approximately a factor of two. However, this discrepancy has not yet been resolved and we have used Lotz's compilation here.) The value for $\mathrm{n}_{\mathrm{e}} \mathrm{T}^{\mathrm{j}}$ of about $10^{8} \mathrm{sec}^{-\mathrm{cm}^{-3}}$ for both carbon and aluminum ions leads to a loss time of about $300 \mu \mathrm{sec}$, assuming an electron density in the surface plasma of $3 \times 10^{11} \mathrm{~cm}^{-3}$.

Using the results in Table $I$ and assuming that the reflux for hydrogen is the same as for impurities in the surface, we may calculate the power expended in the surface plasma. With surface plasma density averaging $3 \times 10^{11} \mathrm{~cm}^{-3}, \mathrm{n}_{\mathrm{e}} \mathrm{t} \approx 10^{8} \mathrm{~cm}^{-3} \mathrm{sec}, \sim 100 \mathrm{eV}$ of cnergy loss for an electron-proton pair (including ionization energy and kinetic energy. of both particles), and surface plasma volume about three-fourths of the total volume (1350 liters) the power loss from wall reflux is calculated to be $15 \mathrm{~kW}$.

The total microwave power used in these runs was $6 \mathrm{~kW}$ at $10.6 \mathrm{GHz}$ and $50 \mathrm{~kW}$ at $18 \mathrm{GHz}$. The fraction of the total volume occupied by the surface plasma is naturally dependent on the drift surface configuration, which will be modified in planned future experiments; thus, the rather 
large fractional power expended to sustain this relatively cold part of the plasma is not expected to be typical of future experiments.

An attempt was made to measure carbon ion densities in the toroidal plasma by looking for the 2275- $\AA$ line from the triplet states of C V which was unobserved. The upper limit was a brightness of $3 \times 10^{9}$ photons $\mathrm{sec}^{-1} \mathrm{~cm}^{-2} \mathrm{sr}^{-1}$. This line has the same upper level as the 40.7- $\AA$ transition from the ground state. Because the population of the upper level comes initially from a $300-\mathrm{eV}$ transition, the core plasma should be much more effective in exciting this level than the surface plasma.

The population of the triplet states from the singlet ground state in helium-1ike ions has been studied by Elton and Köppendörfer [10], Prasad and E1-Menshawy [11], and Kunze et al. [12]. All these authors find that the excitation rate coefficients to the triplet levels are about half the rate coefficients to the singlet states, even though the singlet-triplet radiative transitions are spin-forbidden. Using these data, the radiative transition rate for the ${ }^{1} \mathrm{~S}-{ }^{3} \mathrm{P}$ transition calculated by Elton [13] and by Drake and Dalgarno [14] $\left(\mathrm{A}_{\mathrm{ki}}=0.26 \times 10^{8} \mathrm{sec}^{-1}\right)$, and the value for the $2274-\AA{ }^{3} S-{ }^{3} \mathrm{P}$ transition given by wiese et al. [4] $\left(A_{k i}=0.565 \times 10^{8} \cdot \mathrm{sec}^{-1}\right)$, we may place upper limits on the density of C V.

Assuming an $\mathrm{n}_{\mathrm{C}} \mathrm{T}$ for $\mathrm{C} \mathrm{V}$ to be the same in the surface plasma as measured for the lower charge states and using the measured C IV density and Eq. (4), we find the predicted $2275-\AA$ radiation to be well below detectable levels, as expected. Therefore, the absence of observable C V light is in agreement with the measured C IV density. 
For the case of the toroidal plasma, the situation is somewhat different. The loss time for this plasma should be much longer and the excitation rate much higher than in the surface plasma. Table II shows the upper limit on integrated column density of $\mathrm{n}_{\mathrm{e}} \mathrm{n}_{\mathrm{C}} \mathrm{v}$ for a chord passing through the center of the cavity and an assumed 150-eV temperature.

If one assumes the toroidal C IV density to be equal to the surface C IV density, the absence of a measurable $\mathrm{C} \mathrm{V}$ signal would require the $\mathrm{n}_{\mathrm{e}}{ }^{\top} \mathrm{C} \mathrm{V}$ of the core plasma to be less than approximately $10^{8} \mathrm{~cm}^{-3} \mathrm{sec}$, the same value or less than that measured for the surface plasma. However, for hydrogen in the core plasma, $\mathrm{n}_{\mathrm{e}}^{\mathrm{T}}$ is known to be approx- 1 imately $10^{11} \mathrm{~cm}^{-3} \cdot \mathrm{sec}^{1}$. Hence, either the loss rates for impurities in the core plasma must greatly exceed (by $\sim 10^{3}$ ) those of hydrogen because of unknown mechanisms, or (more likely) the toroidal C IV density is much less than the surface C IV density.

For a chord passing through the center of the cavity where the electron line density is $\mathrm{n}_{\mathrm{e}}{ }^{\ell} 2 \times 10^{13} \mathrm{~cm}^{2}$ and $\mathrm{T}_{\mathrm{e}}>150 \mathrm{eV}$, assuming that $\mathrm{n}_{\mathrm{e}}{ }^{\mathrm{C}} \mathrm{V}$ is the same as for hydrogen ions in the toroidal plasma, we would estimate trom Eq. (2)

$\frac{\mathrm{n}(\mathrm{C} \text { V })}{\mathrm{n}(\mathrm{C} \text { IV })} \sim 50$

With this density ratio, since we observe no light from $\mathrm{C}$, the light intensity observed from C IV. must all uriginale outside the corc.

The upper limit on $C V$ density combined with an assumed $n_{e}{ }^{\top}$ of $10^{11} \mathrm{~cm}^{-3} \mathrm{sec}$ for the core plasma allows one to estimate [using Eq. (4)] the total carbon ion density in the core plasma as being less than $6 \times 10^{-5}$ of the electron density. It is not unreasonable to assume 
that there is even less aluminum impurity in the core plasma, as this is true of the surface plasma. In the surface plasma, where the electron density averages $3 \times 10^{11} \mathrm{~cm}^{-3}$, the total carbon impurity density amounts to $2 \times 10^{-3}$ of the electron density. Including an estimate for AI IV, the total aluminum impurity density is $5 \times 10^{-4}$ of the electron density in the surface plasma.

Summarizing the results of these measurements, spatial scans of the impurity radiation in the ultraviolet from EBT show impurity loss times in the surface plasma on the order of $300 \mu \mathrm{sec}$ and also show that about one fourth of the input power supports the reflux of surface plasma from the walls. Absence of a detectable signal from the $2274-\AA$ line of $C V$ indicates that the core plasma is almost entirely free of impurities. 


\section{REFERENCES}

[1] DANDL, R. A., EASON, H. 0., GUEST, G.E., HEDRICK, C. L., IKEGAMI, H., NELSON, D. B., Plasma confinement and heating in the ELMO Bumpy Torus (EBT), in Plasma Physics and Controlled Nuclear Fusion Research (Proc. 5th Int. Conf. Tokyo, 1974) 2, IAEA, Vienna (1975) 141; HEDRICK, C. L., DANDL, R. A., COBBLE, J. A., DORY, R. A., EASON, H. 0., IIIARRIS, E. G., HASTE, G. R., IKEGAMI, H., JAEGER, E. P., LAZAR, N. II., MCNEILL, D. H., McAlEES, D. G., NELSON, D. B..,

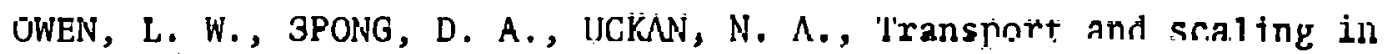
the ELMO Bumpy Torus (EBT), Paper CN-35/D7 presented at the Sixth Int. Conf. on Plasma Physics and Controlied Nuclear Fusion Research, Berchtesgaden, Federal Republic of Germany, October 6-13, 1976.

[2] FAstie, W. G., KERR, D. E., App1. Opt. 14 (1975) 2133.

[3] SEATON, M. J., The theory of excitation and ionization by electron impact, in Atomic and Molecular Processes, ed. by BATES, D. R., Academic Press, New York (1962).

[4] WIESE, W. L., SMITH, M. W., GLENNON, P: M., NSRDS-NBS 4, vol. 1, National Bureau of Standards, Washington, D. C. (1966).

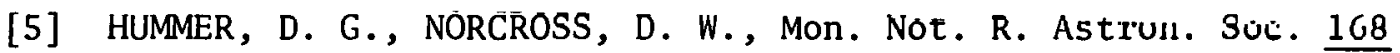
(1974) 263 .

[6] VAN REGEMORTER, H., Astrophys. J. 136 (1962) 912.

[7] LOTZ, W., Astrophys. J. Supp1. Ser. 128 (1967) 207.

[8] LOTZ, W., Z. Phys. 216 (1968) 241.

[9] KUNZE, H. J., Phys. Rev. A $\underline{3}$ (1971) $93 \overline{7}$.

[10] ELTON, R. C., KÖPPENDÖRFER, W. W., Phys. Rev. 160 (1967) 194. 
[11] PRASAd, A. N., El-MenShaWY, M. F., J. Phys. B (Series 2) 1 (1968) 471.

[12] HUZE, H. J., GABRIEL, A. H., GRIEM, H. R., in Physics of Electronic and Atomic Collisions (Proc. 5th Int. Conf. Leningrad, 1967), p. 62 .

[13] EltoN, R. C., Astrophys. J. 148 (1967) 573.

[14] DRAKE, G.W.F., DALGARNO, A., Astrophys. J. 157 (1969) 459. 
TABLE I

$$
\begin{gathered}
\mathrm{n}_{\mathrm{e}} \mathrm{n}_{\mathrm{i}} \times \ell\left(10^{20} \mathrm{~cm}^{-5}\right) \\
(\mathrm{T}=50 \mathrm{eV})
\end{gathered}
$$

\begin{tabular}{l|llll} 
Species & $0^{\circ}$ & $10^{\circ}$ & $20^{\circ}$ & $30^{\circ}$ \\
\hline C II & 23 & 13 & 10 & 4.5 \\
C III & 34 & 26 & 13 & 5.8 \\
C IV & 16 & 15 & 5.0 & 2.0 \\
C V $(150 \mathrm{eV})$ & $<5.4$ & & & \\
A1 II & 3.8 & 3.4 & 1.3 & 0.54 \\
A1 III & 7.6 & 7.5 & 1.2 & 0.67
\end{tabular}

TABLE II

$$
\mathrm{n}_{\mathrm{e}^{\top} \mathrm{i}}\left(10^{8} \mathrm{~cm}^{-3}-\mathrm{sec}\right)
$$

\begin{tabular}{l|llll} 
& & & & \\
Species & $0^{\circ}$ & $10^{\circ}$ & $20^{\circ}$ & $30^{\circ}$ \\
\hline C III & 1.3 & 1.2 & 0.96 & 1.1 \\
C IV & 1.2 & 1.6 & 1.0 & 0.85 \\
Al III & 1.2 & 1.5 & 0.37 & 0.59
\end{tabular}




\section{Figure Captions}

Fig. 1. Geometry for optical scanning.

Fig. 2. Typical spatial scan profiles. Peaks are normalized to a value of $10 . X$ is the distance from the center of the vacuum cavity to the scanning chord. 


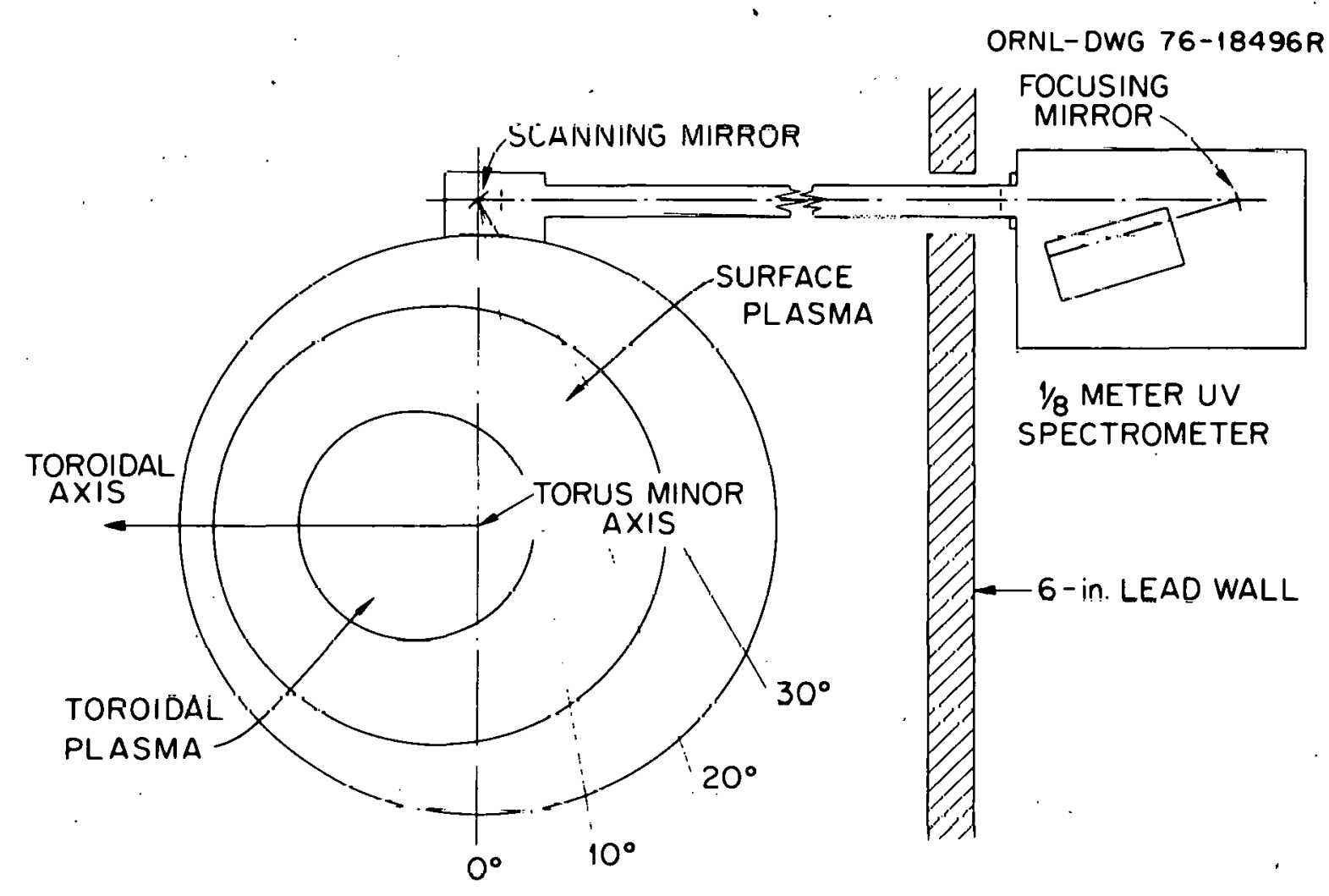

Fig. 1. Geometry for optical scanning. 


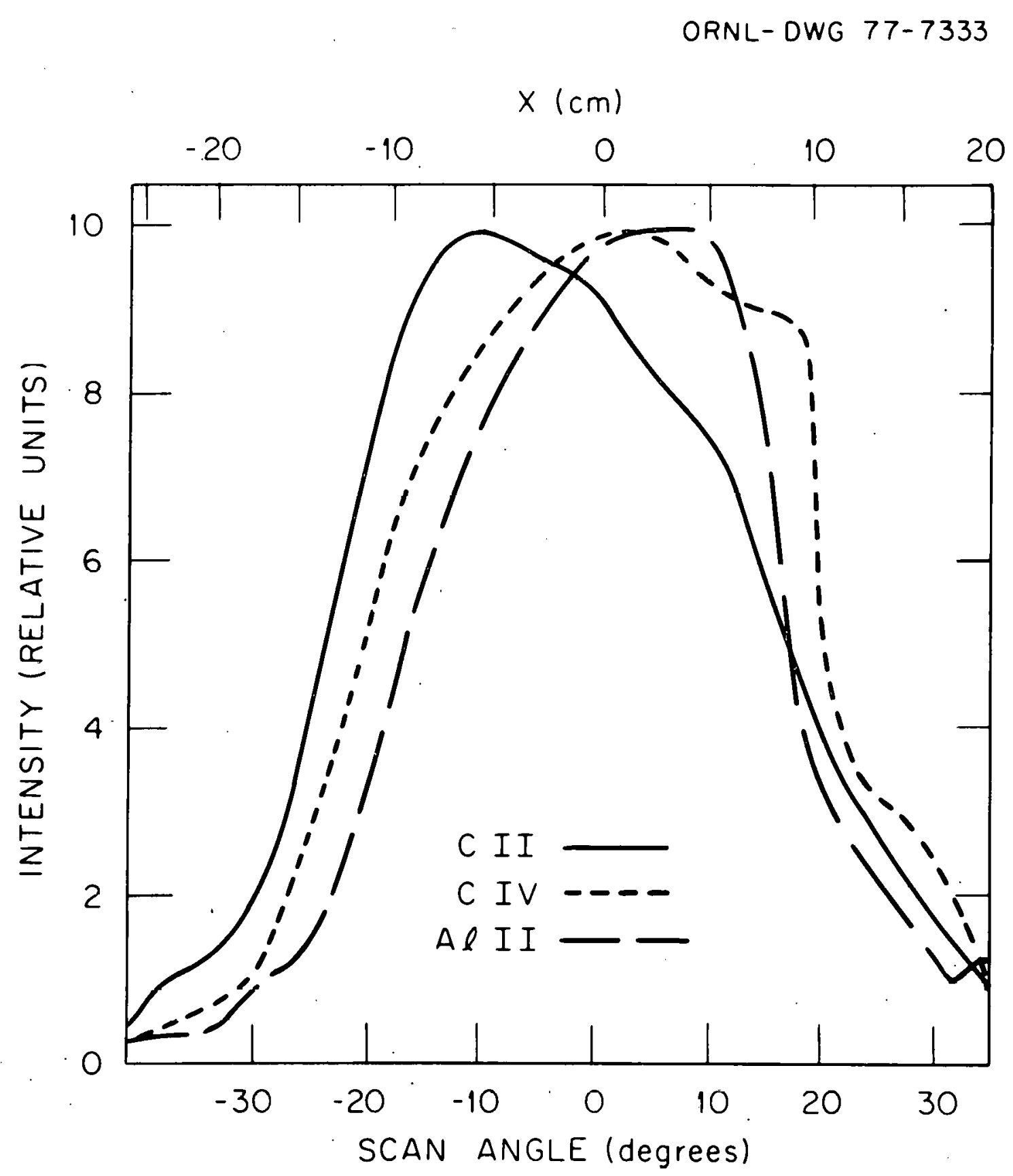

F1g. 2: Typical spatial scan profiles. Peaks are normalized to a value of $10 . x$ is the distance from the center of the vacuum cavity to the scanning chord. 


\section{THIS PAGE \\ WAS INTENTIONALLY \\ LEFT BLANK}


ORNL/TM-5899

\section{INTERNAL DISTRIBUTION}

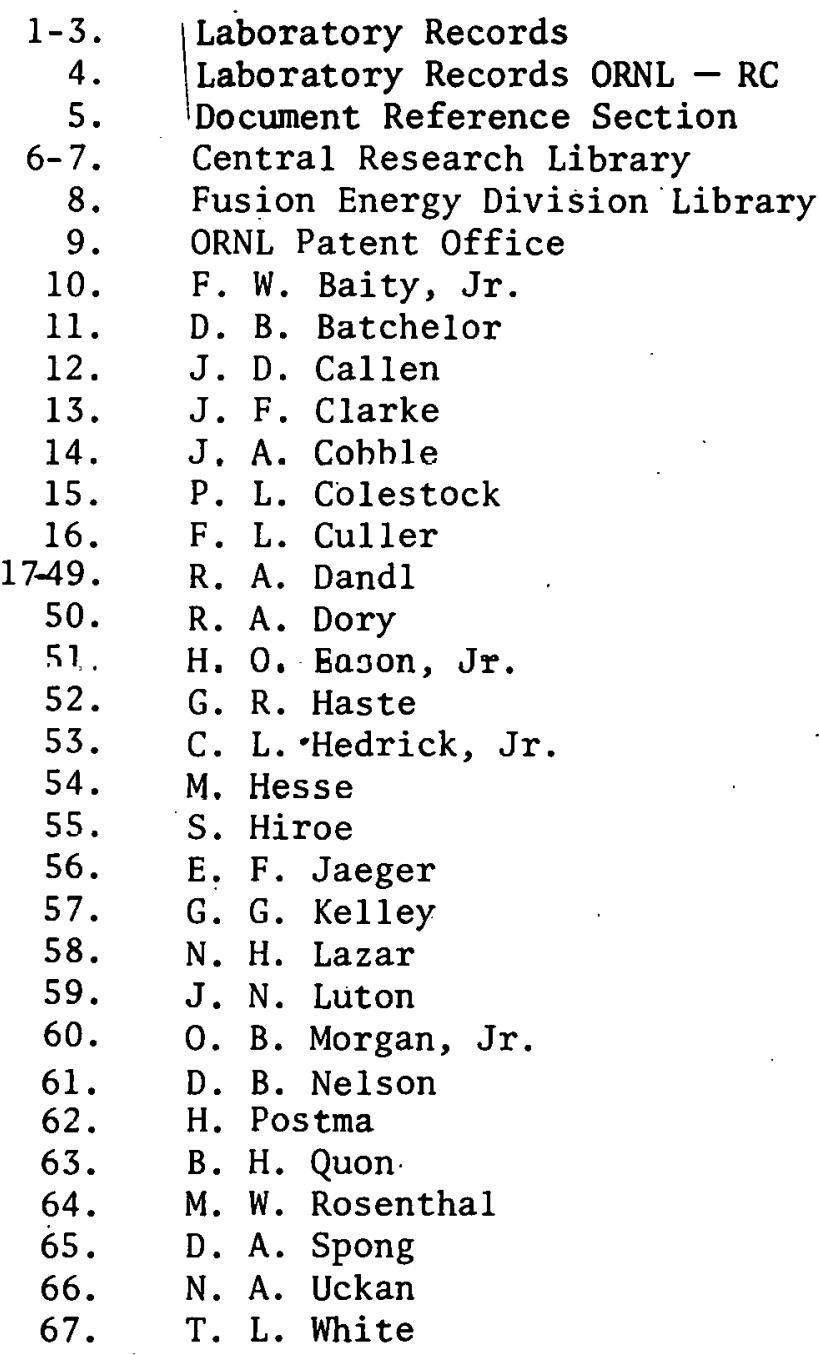

EXTERNAL DISTRIBUTION

68. Dr. Charles Baker, Fusion Engineering Dept., General Atomic Company, P. O. Box 81608, San Diego, CA. 92138

69. Dr. Jack W. Beal, Office of Confinement Systems, M/S G-234, Division of Magnetic Fusion Energy, U. S. Energy Research and Development Administration, Washington, DC 20545

70. Dr. T. Consoli, Centre d'Etudes Nucléaịres de Grenoble, B P 85 Centre de Tri, 38041 Grenoble Cedex, Grenoble, France

71. Dr. R. C. Davidson, Applied Plasma Physics Branch, M/S G-234, Division of Magnetic Fusion Energy, U. S. Energy Research and Development Administration, Washington, DC 20545 
72. Dr. S. 0. Dean, Office of Confinement Systems, M/S G-234, Division of Magnetic Fusion Energy, U. S. Energy Research and Development Administration, Washington, DC 20545

73. Dr. James F. Decker, Applied Plasma Physics Branch, M/S G-234, Division of Magnetic Fusion Energy, U. S. Energy Research and Development Administration, Washington, DC 20545

74. Dr. David A. Dingee, Manager, Fusion Program, Batelle-Northwest Batelle Boulevard, Richland, Washington 99352

75. Dr. William R. Ellis, Jr., Advanced Fusion Systems Branch, Division of Magnetic Fusion Energy, M/S G-234, U. S. Energy Research and Development Administration, Washington, DC 20545

76. Dr. T. K. Fowler, L-382, Univ. of Califurnia, Lawrence Liver-more Laboratory, P. 0. Box 808, Livermore, CA 94550

77. Dr. M. Fujiwara, Institute of Plasma Physics, Nagoya University, Nagoya $\underline{464}$ Japan

78. Dr. H. P. Furth, Princetion Univ., Plasma Physics Laboratory, P. 0. Box 451, Princeton, NJ 08540

79. Dr. Roy W. Gould, Dept. of Applied Physics, California Institute of Technology, Pasadena, CA 91109

80. Dr. Gareth E. Guest, General Átom1c Company, P. 0. Box 81608, San Diego, CA 92138

81. Dr. E. G. Harris, Dept. of Physics, Univ. of Tennessee, Knoxville, TN 37916

82. Dr. R. L. Hickok, Electrophysics Divisiun, Rönsselaer Polytechnic Institute, Troy, NY 12181

83. Dr. R. L. Hirsch, Science and Technology Dept.,, $125 i$ Ave. of the Americas, New York, NY 10020

84. Dr. H. Ikegami, Institute of Plasma Physics, Nagoya Univ., Nagoya 464 Japan

85. Dr. Howard R. Jory, Varian Associates, 611 Hansen Way, Palo Alto, CA 94303

86. Dr. A. Kadish, Division of Magnetic Fusion Energy, M/A G-234, U.S. Energy Research and Development Administration, Washington, DC 20545 
87. Dr. Edwin E. Kintner, Division of Magnetic Fusion Energy, M/S G234, U.S. Energy Research and Development Administration, Washington, DC 20545

88. Dr. Nicholas A. Krall, Science Applications, Inc., 1200 Prospect Street, Box 2351, La Jo1la, CA 92037

89. Dr. H. W. Moos, Department of Physics, Johns Hopkins Univ., Baltimore, MD 21218

90. Dr. Kenneth G. Moses, Chief, Reactor Engineering Branch, Office of the Assistant Director for Technical Projects, Division of Magnetic Fusion Energy, U.S. Energy Research and Development Administration, Washington, DC 20545

91. Dr. Erol Oktay, Division of Magnetic Fusion Energy, M/S G234, U.S. Energy Research and Development Administration, Washington, DC 20545

92. Dr. Robert E. Price, Division of Magnetic Fusion Energy, M/S G-234, U.S. Energy Research and Development Administration, Washington, DC 20545

93. Dr. David J. Rose, Dept. of Nuclear Engineering, Massachusetts Institute of Technology, Cambridge, MA 02139

94. Mr. H. Stanley Staten, Engineering Design \& Component Development Branch, D \& T Program, Division of Magnetic Fusion Energy, M/S G-234, U.S. Energy Research and Development Administration, Washington, DC 20545

95. Dr. A. Straprans, Varian Associates, 611 Hansen Way, Palo Alto, CA 94303

96. Dr. Larry Stewart, Princeton Plasma Physics Lab, P. 0. Box 451, Princeton, NJ 08540

97. Dr. R. S. Symons, Varian Associates, 611 Hansen Way, Palo Alto, CA 94303

98. Dr. E. S. Warden, Dept. of Physics, Johns Hopkins Univ., Baltimore, MD 21218

99. Dr. J. M. Williams, Division of Magnetic Fusion Energy, M/S G-234, U.S. Energy Research and Develupment Administration, Washington, DC 20545

100. Dr. Herbert H. Woodson, Dept. of Electrical Engineering, The Univ. of Texas at Austin, Austin, TX 78712 
101. Director, Research and Technical Support Division, ERDA-ORO, P. O. Box E, Oak Ridge, TN 37830

102-128. Technical Information Center, P. 0. Box 62, Oak Ridge, TN 37830 